2 Postma DS, Rabe KF. The Asthma-COPD overlap syndrome. N Engl J Med 2015; 373: 1241-1249.

3 Vestbo J, Anderson W, Coxson HO, et al. Evaluation of COPD longitudinally to identify predictive surrogate end-points (ECLIPSE). Eur Respir J 2008; 31: 869-873.

4 Ferris BG. Epidemiologhy Standardizaton Project (American Thoracic Society). Am Rev Respir Dis 1978; 118: 1-120.

5 Agusti A, Edwards LD, Rennard SI, et al. Persistent systemic inflammation is associated with poor clinical outcomes in COPD: A novel phenotype. PLoS One 2012; 7: e37483.

6 Shaya FT, Dongyi D, Akazawa MO, et al. Burden of concomitant asthma and COPD in a Medicaid population. Chest 2008; 134: 14-19.

7 Hardin M, Silverman EK, Barr RG, et al. The clinical features of the overlap between COPD and asthma. Respir Res 2011; 12: 127.

8 Hardin M, Cho M, McDonald ML, et al. The clinical and genetic features of COPD-asthma overlap syndrome. Eur Respir J 2014; 44: 341-350.

9 Menezes AM, Montes de Oca M, Perez-Padilla R, et al. Increased risk of exacerbation and hospitalization in subjects with an overlap phenotype: COPD-asthma. Chest 2014; 145: 297-304.

10 Iwamoto $\mathrm{H}$, Gao J, Koskela J, et al. Differences in plasma and sputum biomarkers between COPD and COPD-asthma overlap. Eur Respir J 2014; 43: 421-429.

11 Diaz-Guzman E, Khosravi M, Mannino DM. Asthma, chronic obstructive pulmonary disease, and mortality in the U.S. population. COPD 2011; 8: 400-407.

12 Kitaguchi Y, Komatsu Y, Fujimoto K, et al. Sputum eosinophilia can predict responsiveness to inhaled corticosteroid treatment in patients with overlap syndrome of COPD and asthma. Int J Chron Obstruct Pulmon Dis 2012; 7: 283-289.

13 Albert P, Agusti A, Edwards L, et al. Bronchodilator responsiveness as a phenotypic characteristic of established chronic obstructive pulmonary disease. Thorax 2012; 67: 701-708.

\title{
Blood eosinophil count to predict bronchial eosinophilic inflammation in COPD
}

To the Editor:

Chronic obstructive pulmonary disease (COPD) is an inflammatory disease of the airways. There is evidence that maintenance treatment with inhaled corticosteroids (ICS) in COPD results in a reduction in the mean rate of exacerbations, and improvement in quality of life and lung function [1]. However, ICS therapy has been associated with increased risk of oropharyngeal candidiasis, hoarseness and pneumonia [1]. In COPD, ICS are now recommended in cases of frequent exacerbations and severe obstruction [2].

Even if neutrophilic inflammation is conspicuous in the airways of most COPD and related to the severity of airway obstruction [3], some patients may exhibit raised airway eosinophilic inflammation [4, 5], and those patients show the greater response to a short course of oral [4] and inhaled corticoids [6]. A strategy that focused on sputum eosinophils to adjust dose of ICS and oral glucocorticoids in COPD proved to reduce exacerbation and hospitalisation [7]. Given the difficulty of applying the technique of induced sputum in clinical practice, there is a need to find a biomarker to identify sputum eosinophils in COPD, as has been done in asthma.

Raised blood eosinophil count is a common finding in COPD (37.4\% with persistent blood eosinophil count $\geqslant 2 \%$ ) [8] and seems a promising biomarker to predict the response of COPD patients to ICS [9, 10]. Furthermore, blood eosinophil count $>2 \%$ during an exacerbation was found to predict the utility of systemic corticoids to accelerate recovery [11]. Likewise, this threshold predicted that chronic treatment with ICS added to long-acting $\beta$-agonists (LABA) would prevent exacerbation [9]. Clinical benefit from maintenance treatment with ICS in COPD has recently been found to be particularly clear when the blood eosinophil count was $>280$ per $\mu \mathrm{L}[10]$.

In contrast to asthma, there are no data in the literature on the ability and thresholds of blood eosinophil count to reflect bronchial eosinophilic inflammation in COPD.

We conducted a retrospective study of 155 consecutive COPD patients seen at the COPD clinic of a university hospital (CHU Sart-Tilman, Liege, Belgium), where COPD was defined as a post-bronchodilation forced expiratory volume in $1 \mathrm{~s}(\mathrm{FEV} 1) /$ forced vital capacity $(\mathrm{FVC})$ ratio $<70 \%$. Patients filled in the COPD Assessment Test (CAT) questionnaire and underwent exhaled nitric oxide fraction ( $F$ eNO) measurement followed by spirometry, sputum induction and blood sampling on the same day during a 1-h visit. Data are 
presented as mean \pm SD or mean \pm SEM for continuous variables; median (interquartile range (IQR)) was preferred for skewed distributions. For categorical variables, the number of observations and percentages are given in each category. By constructing receiver operating characteristic (ROC) curves, we identified a blood eosinophil count cut-off point, either taken as a percentage or as absolute value, for identification of sputum eosinophil count $\geqslant 3 \%$, in stable COPD patients and in a subpopulation treated with high doses of ICS (inhaled propionate fluticasone $\geqslant 500 \mu \mathrm{g}$ per day). We also looked at the prediction of sputum eosinophilic inflammation using FeNO and total IgE levels as we previously showed those factors to be good predictors of sputum eosinophilia in asthmatics [12]. The protocol was approved by the Hospitalo-Facultaire Universitaire ethics committee, Liege (institutional review board 2005/181).

Our COPD population included 155 patients aged mean \pm SD $61 \pm 10$ years, of whom 104 were males, $43 \%$ current smokers and 52\% ex-smokers. Median (IQR) post-bronchodilator FEV1 and FEV1/FVC were found to be 56\% (52-62\%) predicted and 53\% (48-55\%), respectively. CAT score was 21 (6-34) with $97 \%$ of patients having a score $\geqslant 10$. Blood eosinophils counts were $160(135-187)$ per $\mu \mathrm{L}$ or $2 \%(1.7-$ 2.3\%). Sputum eosinophil and neutrophil counts were $1.4 \%(1-2 \%)$ and $71.3 \%(66-76 \%)$, respectively. 58 (37\%) out of 155 patients had $>3 \%$ sputum eosinophils. FeNO was 17 (15-19) ppb and total serum IgE was $79(52-130) \mathrm{kU} \cdot \mathrm{L}^{-1}$. In our population, $29 \%$ were steroid naïve, $15 \%$ were treated with low doses of ICS, $24 \%$ with moderate doses of ICS and $32 \%$ with high doses of ICS. $5 \%$ were treated with chronic oral corticosteroids. $75 \%$ received long-acting $\beta_{2}$-agonists while $50 \%$ received long-acting antimuscarinic agents. For the whole group, we found that blood eosinophil count $>162$ per $\mu \mathrm{L}$ or $2.6 \%$ was able to identify patients with sputum eosinophil count $\geqslant 3 \%$ (area under the ROC curve (AUC) 0.75 ( $\mathrm{p}<0.0001$, $71 \%$ sensitivity, 67\% specificity) and AUC 0.7 ( $\mathrm{p}<0.0001,53 \%$ sensitivity, $83 \%$ specificity), respectively).

In patients receiving high doses of ICS $(n=50)$, the median blood eosinophil count was 207 per $\mu \mathrm{L}$. The best cut-off value of blood eosinophil count for the prediction of sputum eosinophil count $\geqslant 3 \%$ in this group was 215 per $\mu \mathrm{L}$ (AUC $0.76, \mathrm{p}=0.001,60 \%$ sensitivity, 93\% specificity) or $2.3 \%$ (AUC $0.78, \mathrm{p}<0.0001$, $62 \%$ sensitivity, $94 \%$ specificity).

We found a lower utility of $F$ eNO for the prediction of uncontrolled sputum eosinophilic inflammation in COPD patients (cut-off $24 \mathrm{ppb}$; AUC 0.65, p=0.004, 38\% sensitivity, 91\% specificity). Looking specifically at nonsmokers, the ROC curve identified a FeNO level $>24 \mathrm{ppb}$ as the best cut-off point, giving $42 \%$ sensitivity and $82 \%$ specificity (AUC 0.6 ) in predicting sputum eosinophil count $\geqslant 3 \%$. There was a

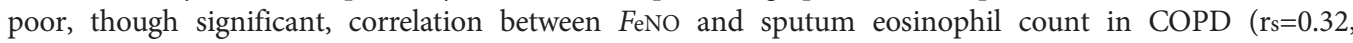
$\mathrm{p}=0.001$ ). By contrast, serum total IgE levels had no ability to discriminate between those with eosinophilic and noneosinophilic COPD (AUC 0.55, p>0.05). Next, we looked at combined FeNO and blood eosinophils as predictors of sputum eosinophilia. When comparing AUCs in the three models (FeNO versus blood eosinophils versus FeNO plus blood eosinophils) (figure 1), combining FeNO and blood eosinophils did not improve the prediction of sputum eosinophilia (AUC 0.77) compared to blood eosinophils alone.

There are no data in the literature on the blood eosinophil thresholds predicting bronchial eosinophilic inflammation in COPD. Here, we provide thresholds in a population of stable COPD and in a subpopulation of COPD patients treated with high doses of ICS. In a population of 155 stable COPD patients, we found that the best cut-off values of blood eosinophil counts to identify a sputum eosinophil count $\geqslant 3 \%$ are 162 per $\mu \mathrm{L}$ or $2.6 \%$. When focusing on COPD patients treated with high doses of ICS, the best cut-off points were 215 per $\mu \mathrm{L}$ or $2.3 \%$. FeNO was able to discriminate between eosinophilic and noneosinophilic inflammation but with lesser accuracy than that previously observed in asthma [13]. The best FeNO threshold was also lower in COPD (24 ppb) than that found in asthmatics (42 ppb) [13]. By

FIGURE 1 Receiver operating characteristic curve analyses of the sensitivity and the specificity of an absolute value of blood eosinophils (best threshold 162 per $\mu \mathrm{L}$ ), exhaled nitric oxide fraction ( $\mathrm{FeNO}$ ), and combined blood eosinophils and FenO for the diagnosis of sputum eosinophilia in chronic obstructive pulmonary disease. AUC: area under the curve.

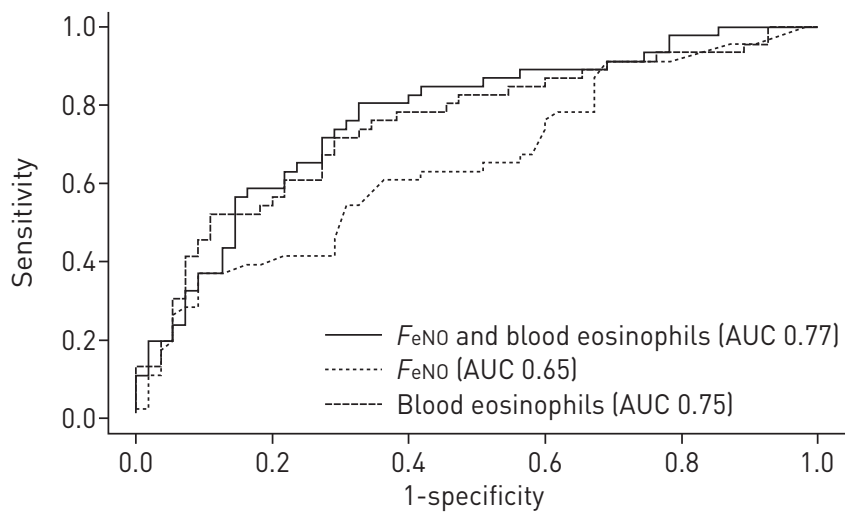


contrast, total serum IgE level was unhelpful in identifying sputum eosinophilia. FeNO did not add value to blood eosinophil count in improving the prediction of sputum eosinophilia.

It is noteworthy that the blood eosinophil thresholds we report here as predicting sputum eosinophilia are very close to those recently shown to predict ability of ICS to prevent exacerbations when combined with LABA in stable COPD in large retrospective study [9].

We think that blood eosinophil counts should be useful to initiate ICS in COPD patients and to adjust ICS dose in those with recurrent exacerbations. Therefore, we believe our data are relevant for the numerous clinicians who have no access to induced sputum analysis, even though we are aware that the thresholds we propose here need to be validated in large-scale prospective studies.

@ERSpublications

Blood eosinophil counts, but not FeNO, may predict airway eosinophilic inflammation http://ow.ly/WXgkA

Florence Schleich ${ }^{1}$, Jean-Louis Corhay ${ }^{1}$ and Renaud Louis ${ }^{1,2}$

${ }^{1} \mathrm{CHU}$ Sart-Tilman, GIGA I ${ }^{3}$, Liege, Belgium. ${ }^{2}$ Université d'Etat de Liège, Liege, Belgium.

Correspondence: Florence Schleich, CHU Sart-Tilman, Sart-Tilman B35, B-4000 Liege, Belgium.

E-mail: fschleich@chu.ulg.ac.be

Received: Oct 072015 | Accepted after revision: Dec 082015 | First published online: Feb 042016

Editorial comment in: Eur Respir J 2016; 47: 1299-1303

Support statement: This work was supported by IAP P7/30. Funding information for this article has been deposited with FundRef.

Conflict of interest: None declared.

\section{References}

1 Yang IA, Clarke MS, Sim EH, et al. Inhaled corticosteroids for stable chronic obstructive pulmonary disease. Cochrane Database Syst Rev 2012; 7: CD002991.

2 Global Initiative for Chronic Obstructive Lung Disease. Global Strategy for the Diagnosis, Management, and Prevention of Chronic Obstructive Pulmonary Disease NHLBI/WHO Workshop Report. Bethesda, National Institutes of Health, 2001

3 Moermans C, Heinen V, Nguyen M, et al. Local and systemic cellular inflammation and cytokine release in chronic obstructive pulmonary disease. Cytokine 2011; 56: 298-304.

4 Brightling CE, Monteiro W, Ward R, et al. Sputum eosinophilia and short-term response to prednisolone in chronic obstructive pulmonary disease: a randomised controlled trial. Lancet 2000; 356: 1480-1485.

5 Louis RE, Cataldo D, Buckley MG, et al. Evidence of mast-cell activation in a subset of patients with eosinophilic chronic obstructive pulmonary disease. Eur Respir J 2002; 20: 325-331.

6 Brightling CE, McKenna S, Hargadon B, et al. Sputum eosinophilia and the short term response to inhaled mometasone in chronic obstructive pulmonary disease. Thorax 2005; 60: 193-198.

7 Siva R, Green RH, Brightling CE, et al. Eosinophilic airway inflammation and exacerbations of COPD: a randomised controlled trial. Eur Respir J 2007; 29: 906-913.

8 Singh D, Kolsum U, Brightling CE, et al. Eosinophilic inflammation in COPD: prevalence and clinical characteristics. Eur Respir J 2014; 44: 1697-1700.

9 Pascoe S, Locantore N, Dransfield MT, et al. Blood eosinophil counts, exacerbations, and response to the addition of inhaled fluticasone furoate to vilanterol in patients with chronic obstructive pulmonary disease: a secondary analysis of data from two parallel randomised controlled trials. Lancet Respir Med 2015; 3: 435-442.

10 Siddiqui SH, Guasconi A, Vestbo J, et al. Blood eosinophils: a biomarker of response to extrafine beclomethasone/ formoterol in chronic obstructive pulmonary disease. Am J Respir Crit Care Med 2015; 192: 523-525.

11 Bafadhel M, McKenna S, Terry S, et al. Blood eosinophils to direct corticosteroid treatment of exacerbations of chronic obstructive pulmonary disease: a randomized placebo-controlled trial. Am J Respir Crit Care Med 2012; 186: $48-55$

12 Schleich FN, Manise M, Sele J, et al. Distribution of sputum cellular phenotype in a large asthma cohort: predicting factors for eosinophilic vs neutrophilic inflammation. BMC Pulm Med 2013; 13: 11.

13 Schleich FN, Seidel L, Sele J, et al. Exhaled nitric oxide thresholds associated with a sputum eosinophil count $\geqslant 3 \%$ in a cohort of unselected patients with asthma. Thorax 2010; 65: 1039-1044. 